\title{
A Study of Laseruler Accuracy and Precision (1986-1987)
}

Ram S. Ramachandran and Kenneth P. Armstrong

June 22, 1989

\section{MOUND}

operated by

П EGূE MOUND APPLIED TECHNOLOGIES

P.O. Box 3000, Miamisburg, Ohio 45343-0987

for the

U. S. DEPARTMENT OF ENERGY

Contract No. DE-AC04-88DP43495 


\section{DISCLAIMER}

This report was prepared as an account of work sponsored by an agency of the United States Government. Neither the Unitert States Government nor any agency thereot. nor any of their employees. makes any warranty. express or implled. or assumes any legal llabillty or responsibillty for the accuracy. completeness, or usefuiness of any infirmation. apparatus. product. or process disclosed. or represents that its use would not Infringe privately owned rights. Reference herein to any specific commercial product. process. or service by trade name. trademark. manufacturer. or otherwise. does not necessarily constitute or imply its endorsement. recommendation. or favoring by the Unlted States Government or any agency thereof. The views and opinions of authors expressed herein do not necessarlly state or reflect those of the United States Government or any agency thereof. 
MLM-MU-89-66-0001

\section{A Study of Laseruler Accuracy and Precision (1986-1987)}

Ram S. Ramachandran and Kenneth P. Armstrong

Issued: June 22, 1989

\section{MOUND}

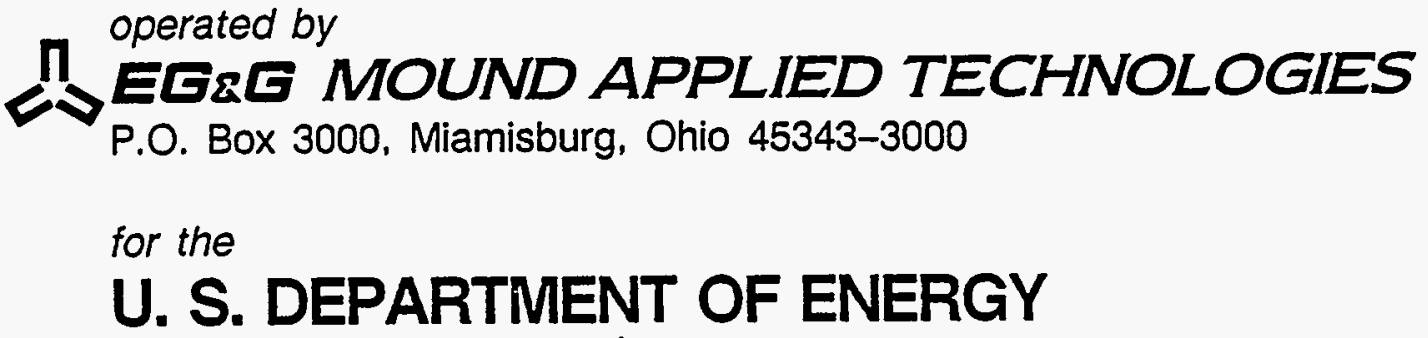

Contract No. DE-AC04-88DP43495 


\section{Contents}

Page

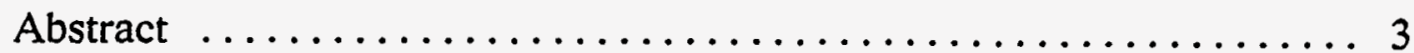

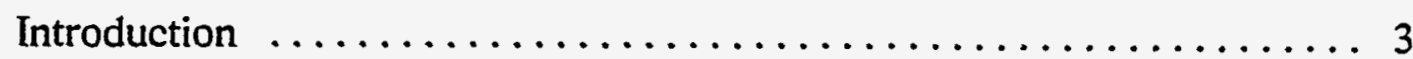

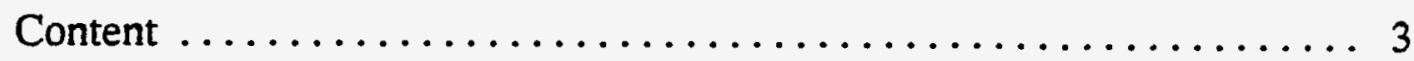

Thickness Measurements Using Laseruler Memo $\ldots \ldots \ldots \ldots \ldots 4$

Laseruler Data Analysis and Recording Memo ............. 11

Laseruler Accuracy and Precision Study Memo ............ 15

SPC on Laseruler Measurements Memo ................ 20

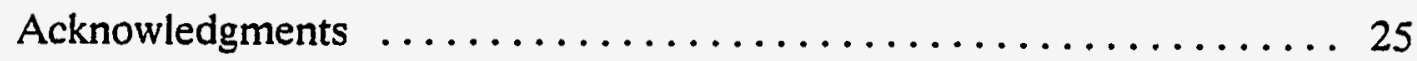

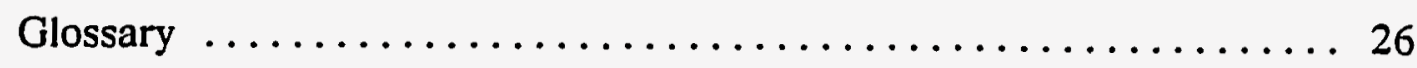

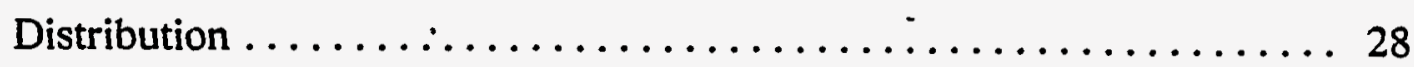




\section{Abstract}

A study was conducted to investigate Laseruler accuracy and precision. Tests were performed on 0.050 -in., 0.100 -in., and 0.120 -in. gauge block standards. Results showed an accuracy of $3.7 \mu$ in. for the 0.12 -in. standard, with higher accuracies for the two thinner blocks. The Laseruler precision was 4.83 $\mu \mathrm{in}$. for the 0.120 -in. standard, $3.83 \mu \mathrm{in}$. for the 0.100 -in. standard, and $4.20 \mu \mathrm{in}$. for the 0.050 -in. standard.

\section{Introduction}

The MC3926 and 1E38 detonators were developed based on studies conducted by Quality, Production, and Development personnel. In the early stages of the programs, the tape process studies were documented in memos. To formally record these studies and make them easily available to interested persons, these memos are being compiled as Mound technical reports. This report documents research performed by R. S. Ramachandran in December 1986.

Ramachandran conducted the studies to investigate the accuracy and precision of the Laseruler, a nondestructive tool used to measure substrate thickness. In this study, the thickness of copper on finished bridge circuits was measured with the Laseruler. Three standard gauge blocks were examined. Analyses showed the Laseruler accuracy to be $3.7 \mu \mathrm{in}$. on the 0.120 -in. standard, $2.8 \mu \mathrm{in}$. on the 0.100 -in. standard, and $1.3 \mu \mathrm{in}$. on the 0.050 -in. standard.

The precision ( 1 sigma), or total standard deviation, of the Laseruler on the gauge block standards was determined to be $4.83 \mu \mathrm{in}$. for the 0.120 -in. standard, $3.83 \mu \mathrm{in}$. for the 0.100 -in. standard, and $4.20 \mu \mathrm{in}$. for the 0.050 -in. standard. A previous study on MAD-1079 bridges had shown an estimated precision of $3.62 \mu \mathrm{in}$. within a $164-\mu \mathrm{in}$. range.

Analysis of the variance showed a significant difference between measurements taken in the morning and evening and also among measurements taken on different days. In addition, a difference in measurements among operators was noted. This was caused by manual manipulation of the standards during the study and should be greatly reduced during normal inspection of bridge circuits because laseruler operation is automated.

\section{Content}

This report comprises four memos (the Laseruler Accuracy and Precision Study memo contains an additional memo) summarizing work performed in the tape process area. The memos are reproduced unedited. 
From: Experimental Design, Nuclear

Operations, S. E. Rigdon
CC. D. B. Armstrong

File

Date: April 29, 1986

Subject: Thickness Measurements Using Laser Ruler

Reference:

To:

R. S. Ramachandran

$\underline{\text { Objective }}$

The objectives of these two experiments were to find the settings of the variables

probe weight in ounces (WEIGHT)

time spent by the probe on the tape in seconds (TIME)

shape, i.e. flat or spherical, of the probe (SHAPE).

which minimize the variability of repeated measurements when using the laser ruler to measure tape thicknesses.

Experimental Designs

The first experimental can be described as follows:

\begin{tabular}{rrr} 
Shape & Time & Weight \\
\hline S & 2 & 2 \\
S & 2 & 4 \\
S & 4 & 2 \\
S & 4 & 4 \\
S & 8 & 4 \\
F & 2 & 2 \\
F & 2 & 4 \\
F & 4 & 2 \\
F & 4 & 4 \\
F & 8 & 2
\end{tabular}

Each of the above combinations was run three times on each of five $1 E-38$ units. For each unit, the average of the three readings and the standard deviation of the three readings were computed. The run order was 
randomized. Note that this design is not totally balanced; there was no run for SHAPE='S', TIME=8 and WEIGHT=2 nor was there a run for SHAPE='F'. TIME $=8$ and WEIGHT $=4$. Originally, these runs were to be performed, however time constraints within one day dictated that only two runs at TIME $=8$ could be performed within one day.

The second experimental plan may be described as follows:

\begin{tabular}{rrr} 
Shape & Time & Veight \\
\hline S & 2 & 2 \\
S & 2 & 4 \\
S & 4 & 2 \\
S & 4 & 4 \\
S & 8 & 2 \\
S & 8 & 2
\end{tabular}

Each combination was run three times on each of five units. Again, the order was randomized.

\section{Analysis}

The standard deviation of the three readings on each of the five units was treated as the response variable. Thus, for the first experiment, there were five responses for each combination of factors, yieiding 50 responses. For the second experiment, there were five responses $f: "$ each combination, yielding 30 responses. While these responses are not nirmally distributed, they should be reasonably close to a normal distribution so that analysis of variance can be performed.

Figure 1 shows, for the first experiment, the average of five standard deviations, each standard deviaiton being based on three readings on the same unit under the same conditions. The red pyramid indicates that a flat probe was used and a green pyramid indicates that a spherical probe was used. From this graph it is apparent that the nat probe yields higher variability. Also, the flat probe showed signs of deforming the surface of the tape. Thus a nat probe is not deyirable. From the first experiment, it cannot be determined whether the variables TIME and WEIGHT affect the variability. For this reason the second experiment was run.

With fewer required runs per day, the second experiment could include two runs at TIME=8. As a result, the second experimental design is balanced. Again in the second experiment, the response variable was the standard deviation of three measurements on a given unit. Since there were five units, there were five standard deviations at each combination of factors. Figure 2 shows the average of five standard deviations, each standard deviaiton being based on three readings on the same unit under the same 
conditions. Note, in this graph, that the height of the "spikes" are all about the same. Figure 3 shows the actual standard deviations. Since the graphs are inconclusive, an analysis of variance was periormed using the standard deviation as the response variable. The analysis of variance table is shown in Table 1. The F-statistics for the TIME and WEIGHT variables are 0.40 and 0.01 , respectively. These are not significant at any reasonable significance level.

\section{Conclusions}

From the first experiment, it can be concluded that probe shape affects the variability of measured thickness, with the spherical probe having smaller variability. The second experiment indicates that neither time nor weight affect the variability of the laser ruler. Thus it is recommended that the laser ruler be operated with a spherical probe at the most economical levels of TIME and WEIGHT, i.e. at TIME $=2 \mathrm{sec}$. and WEIGHT $=2 \mathrm{oz}$.

\section{$\underline{\text { Repeatability Testing }}$}

Once the levels of TIME and WEIGHT are determined, a repeatability test should be performed. An experimental plan for this experiment may be described as follows. Twenty to thirty bridges, manufactured from the process that will be used in Production, should be used. The thickness of each bridge should be gaged three to four times a day for each of three to five days. If four readings per day are done, then two technicians may be employed.

The numbers given above are only rough at this time. Further discussion may result in changes. However, some idea of the magnitude of the next study should now be apparent.

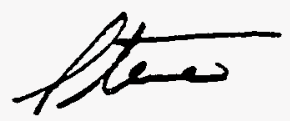

Steve Rigdon 


\section{Average Standard Deviation of 3 Readings on 5} Units for Levels of Probe Shape, Weight and Time

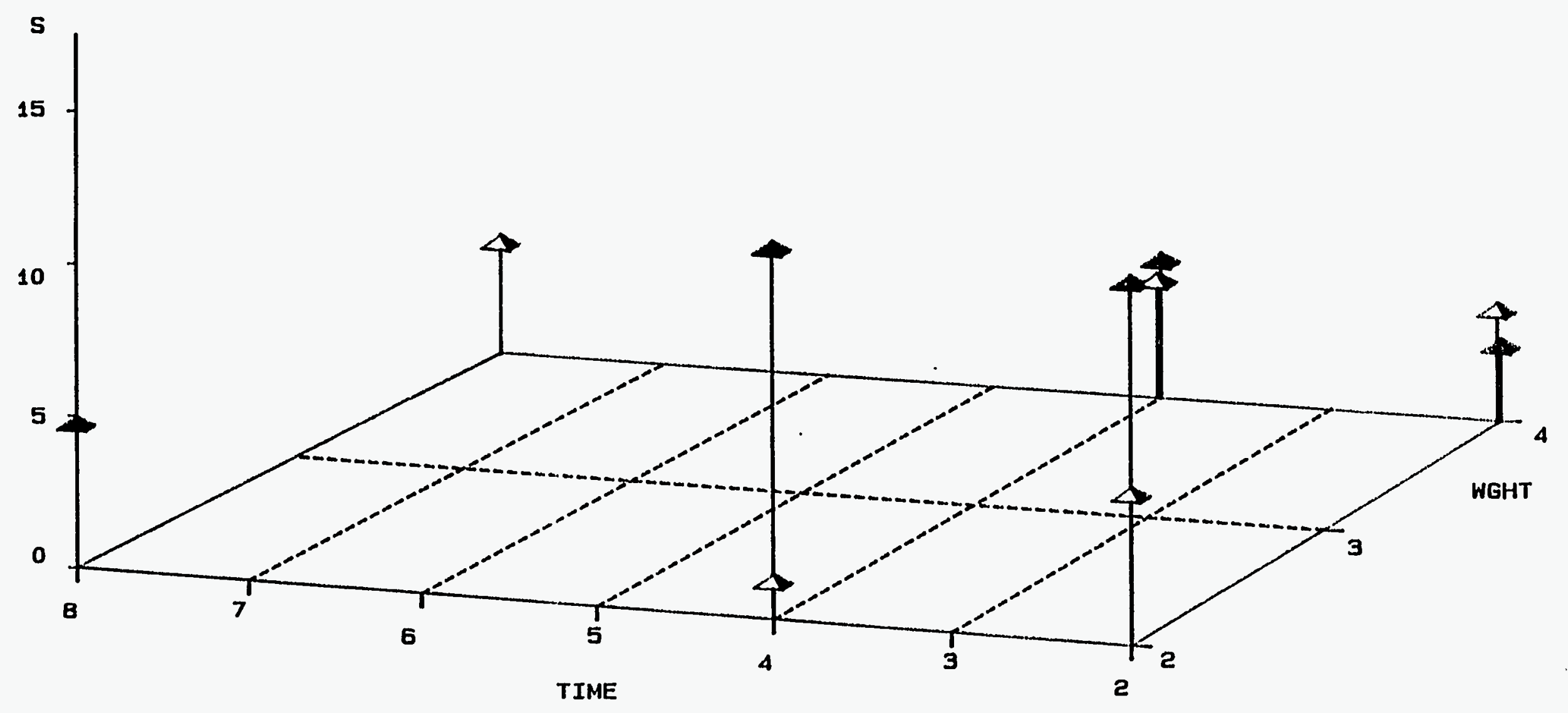

Red - Flat Probe 


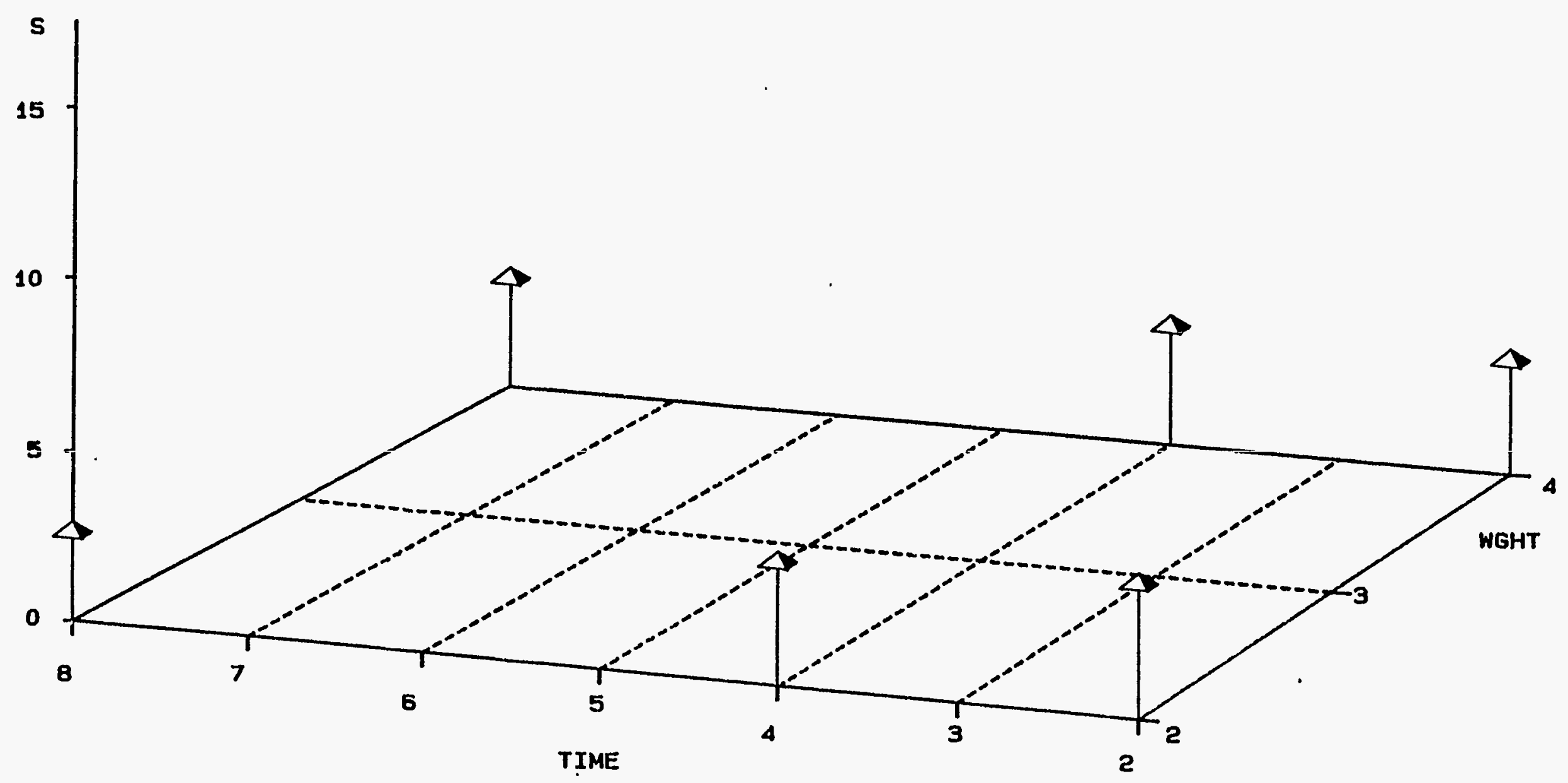

Second Experiment 


\section{Standard Deviations of 3 Readings for Different Levels of Probe Shape, Weight and Time}

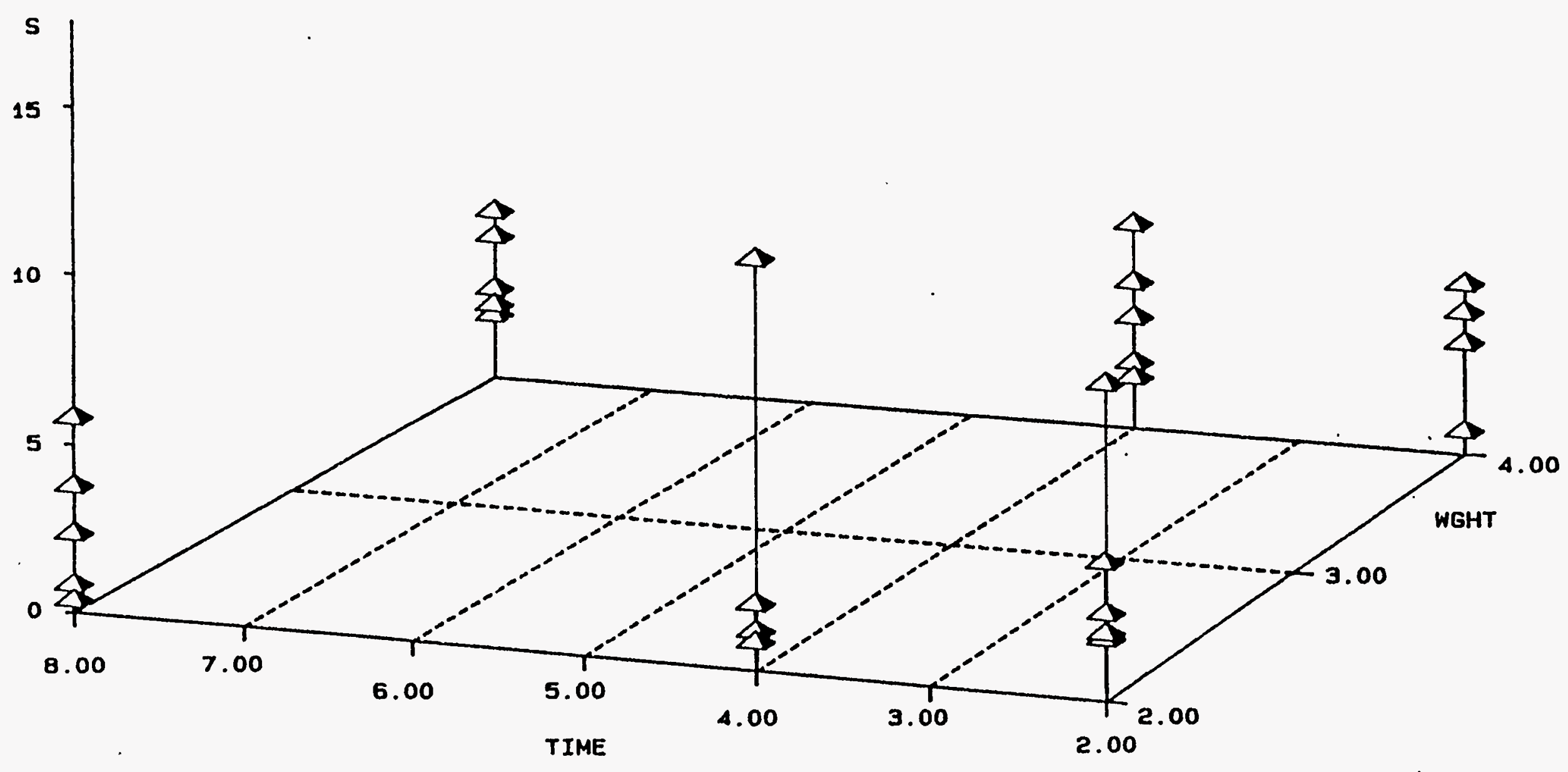


QC Engineering, Administration

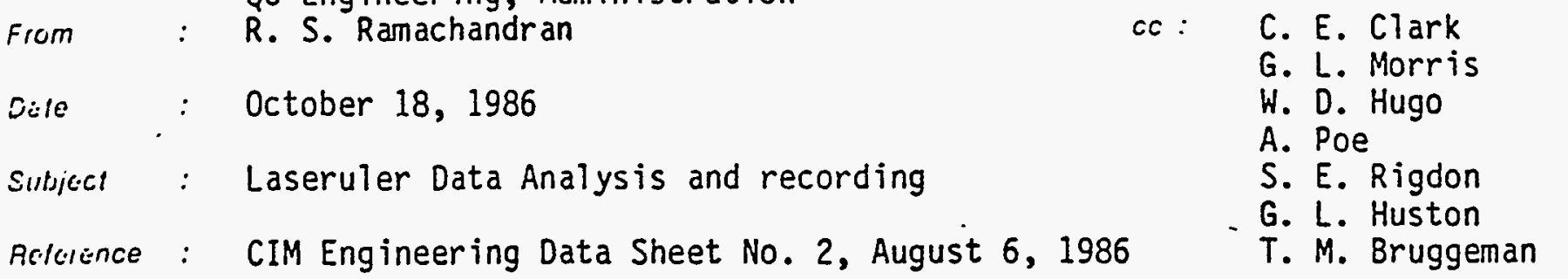

TO : D. E. Wendeln

The following information is provided to support the Computed Aided Inspection justification with regard to the above reference prepared by Advanced Manufacturing Development.

Data analysis from a repeatability study with 28 units of MAD-1079 bridges gave an estimated precision between $+/-3.62$ microinches within 164 microinches range. Measurement error of the Laseruler instrument determined from the designed experiment was 2.74 microinches. Analys is of Variance showed a standard deviation for the variance components as below:

$\begin{array}{ll}\text { Unit-to-unit variation } & -2.95 \text { microinches } \\ \text { Day-to-day variation } & -1.43 \text { microin. } \\ \text { Technician-to-technician }-1.89 \text { microin. } \\ \text { Measurement error } & -2.74 \text { microin. }\end{array}$

Total Measurement variability

excluding the unit variation - 3.62 microinches

Figure 1 shows no significant differences on measurements between day-to-day. The study did exhibit an operator-to-operator variability as determined by the student $t$-test. Also as seen in Figure 2 measurements between operators shifted slightly. Plots for Technician $M$ is shifted to the right and up showing slight higher values than for the Technician $\mathrm{J}$. The attached table provides a summary of recorded data. No significant difference between the first and second readings were noted.

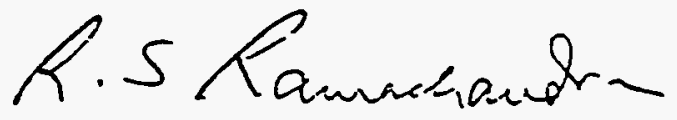

R. S. Ramachandran 
Figure 1 on Laser Ruler: By Day

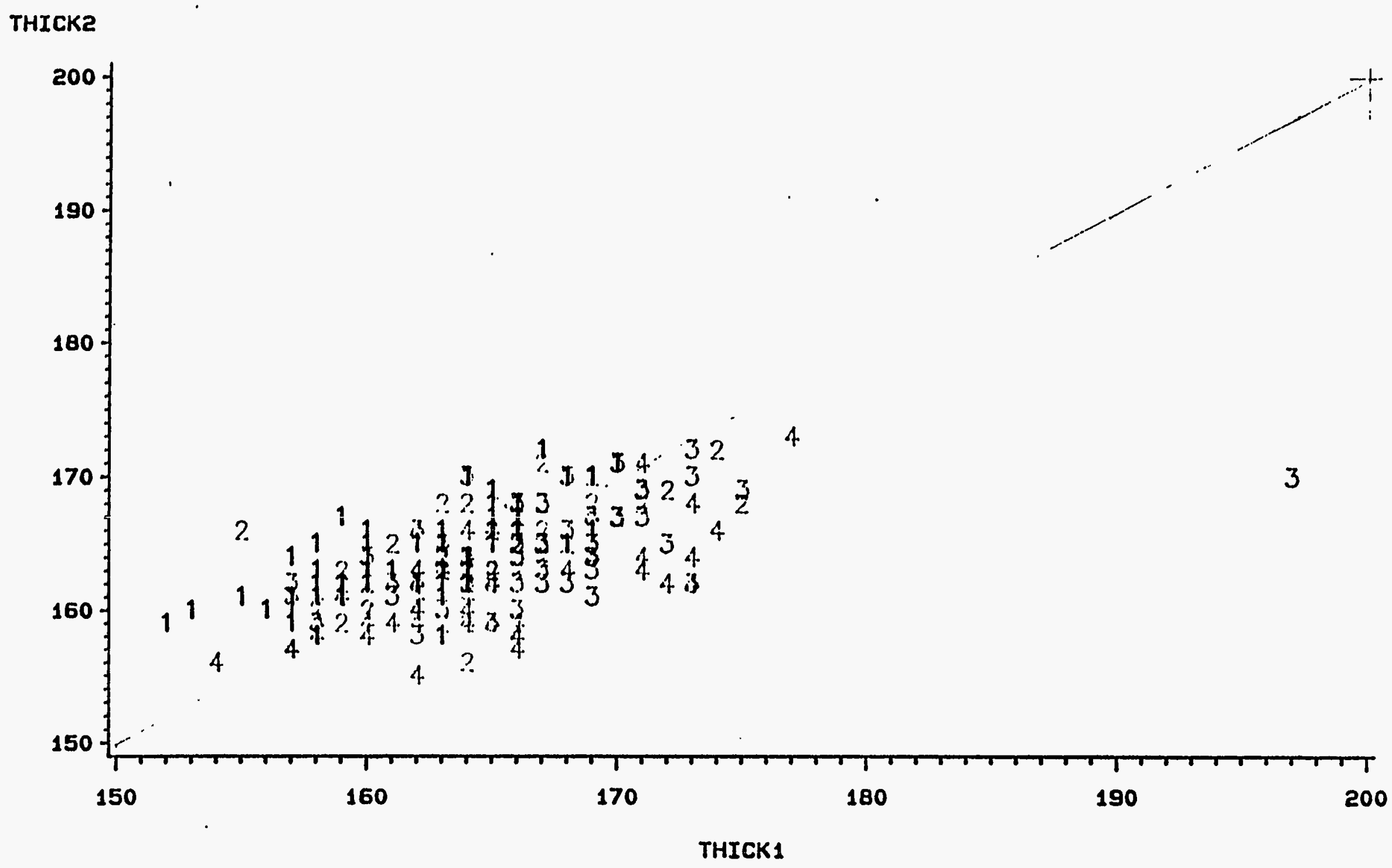

DAY 1111 2.2.2 $3333 \quad 4444$




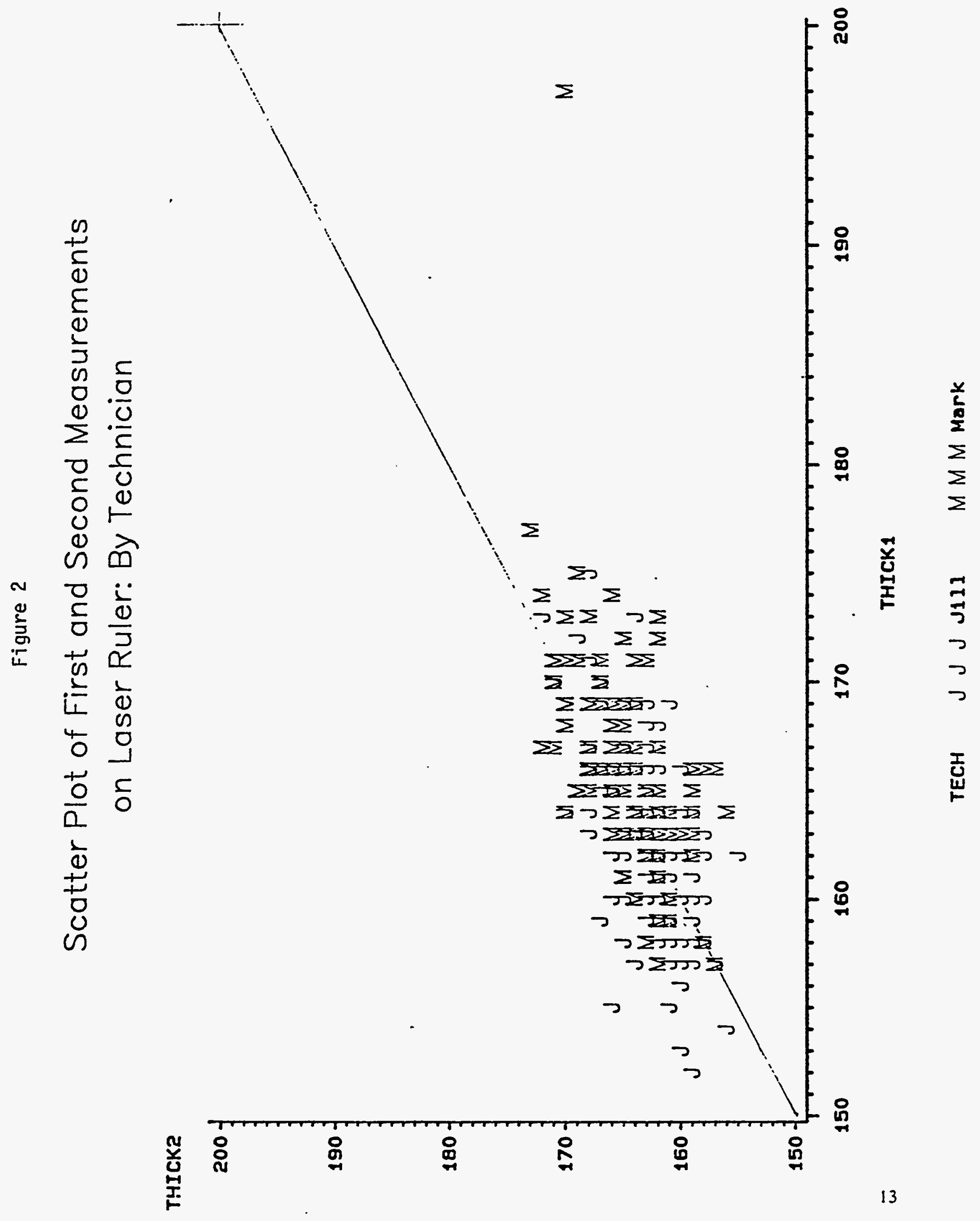


Table

Laseruler measurement study

Statistics for two different runs

Mean*

Std. Dev.

Range

Technician $\mathrm{J}$

First readings

162.62 microin.

163.04 microin.

4.448

3.207

$152.00-175.00$

Second readings

Technician M

First readings

Second readings

166.27 mciroin. 164.75 microin.

4.983

3.750

$157.00-197.00$

$156.00-173.00$

* MAD-1079 bridge thickness measurement averages of 112 test data 


$\begin{array}{ll}\text { From } & \text { R. S. Ramachandran } \\ \text { Date } & \text { : December } 17,1986 \\ \text { Subject : Distribution } & \\ \text { Reference : } & \end{array}$

Attached is the statistical report on the Laseruler accuracy and precision study with the three gauge block standards.

Analysis showed an accuracy of +1.3 microinches maximum bias on the 0.050 inch standard block. It should be noted that the bias increases with the thicker standard blocks. Manufacturer's accuracy specification for the Laseruler is 3 microinches within one inch envelope (1 cubic inch).

The precision (one sigma) of the Laseruler on three standards are 3.83 microinches (.100 inch standard), 4.20 microinches (.050 inches standard), and 4.83 microinches (.120 inch standard). The previous study on MAD 1079 bridge showed an estimated precision of 3.62 microinches within .000164 inches range.

Analys is of variance on the test data showed a significant difference within day (morning and evening measurements) and between days. Also, a statistical difference in measurements between operators was noted. This variation is because of manual manipulation of the gage block in the study. The operator-to-operator variability should be reduced greatiy during the normal inspection of bridge circuits because of the automatic mode of Laseruler operation. Quality Engineering recommends that an environmental enclosure (for humidity/temperature control and to minimize external factors) be installed on the Laseruler at the actual work location to improve the accuracy and precision of measurements. Also, a finite location point on the instrument for the Laseruler probe to measure thickness dimension be considered to further improve the accuracy.

These results satisfy the level of accuracy and precision needed for the thickness measurement of microclad bridge material on Laseruler. In order to maintain the measurement capability and monitor possible trends I suggest that we initiate a control chart scheme with routine measurements on master standards and plot the $x$ bar and $R$ charts on a daily basis. Software modification to include SPC program should be considered to incorporate these control plots. If I can be of any assistance please do not hesitate to contact me.

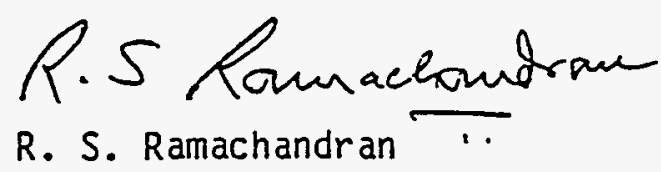




$\begin{array}{lll}\text { From } & : \text { S. E. Rigdon } & \text { cc: D. B. Armstrong } \\ \text { Date } & \vdots \text { December 4, } 1986 & \text { B. T. Leahy } \\ & \text { Eile }\end{array}$

Subject : Laser Ruler Precision \& Accuracy

Reference :

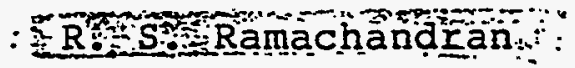

Objective. The objective of this experiment was to study the accuracy and precision of the Laser Ruler.

Experimental Design. Three standards, $0.05,0.10$ and 0.12

inches, were measured 5 times each hour for six hours per day for four days. Two operators measured the parts, each taking either the three morning readings or the three afternoon readings. They alternated taking the morning. and afternoon shifts.

Model The statistical.model is that the reading $Y$ is influenced by the OPERATOR, DAY and TIME within DAY, that is,

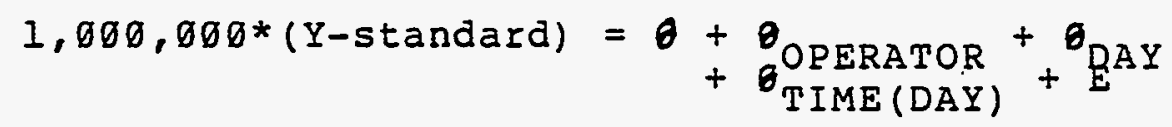

where OOPERATOR, $\theta_{\text {DAY' }} \theta_{\text {TIME }}$ DAY and E are normzlly

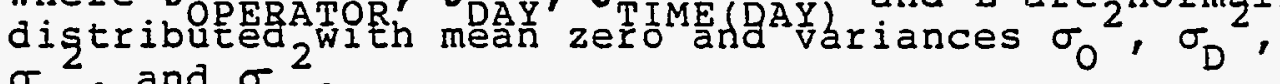
$\sigma_{\mathrm{T}}$, and $\sigma_{\mathrm{E}}^{2}$.

Analysis. Estimates of these variance components are given in the following tables. (The standard deviations are in units of microinches.)

\begin{tabular}{lcc}
0.05 Standard & Variance & Standard Deviation \\
\hline Operator & 0 & 0 \\
Day & 0 & 0. \\
Time (Day) & 15.499 & 3.937 \\
Error & 2.121 & 1.456 \\
Total & 17.620 & 4.198
\end{tabular}

\begin{tabular}{llc} 
0.10 Standard & Variance & Standard Deviation \\
\hline Operator & 0.036 & 0.190 \\
Day & 6.415 & 2.533 \\
Time (Day) & 5.411 & 2.326 \\
Error & 2.829 & 1.682 \\
Total & 14.691 & 3.833
\end{tabular}




\begin{tabular}{llc} 
0.12 Standard & Variance & Standard Deviation \\
\hline Operator & 5.122 & 2.263 \\
Day & 5.170 & 2.274 \\
Time (Day) & 9.176 & 3.629 \\
Error & 3.867 & 1.966 \\
Total & 23.335 & 4.831
\end{tabular}

If the precision is defined as the total standard deviation, including operator-to-operator variability, Day-to-day variability, etc. then the precision of the Laser Ruler is given in the next table. (The units are in microinches, i.e., $10^{-6}$ in.) The accuracy, defined as the average minus the true value of the standard is also given in the table.

\begin{tabular}{ccc} 
Standard & Accuracy & Precision \\
\hline$\emptyset . \emptyset 5$ & +1.3 & 4.198 \\
$9.1 \emptyset$ & +2.8 & 3.833 \\
$\emptyset .12$ & +3.7 & 4.831 \\
\hline
\end{tabular}

Plots of measurement versus run order are given" on the attached plots. There appear to be some trends for some of the sets of readings by operator "S".

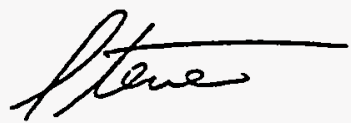

S. E. Rigdon

SER: jW

Attachments 

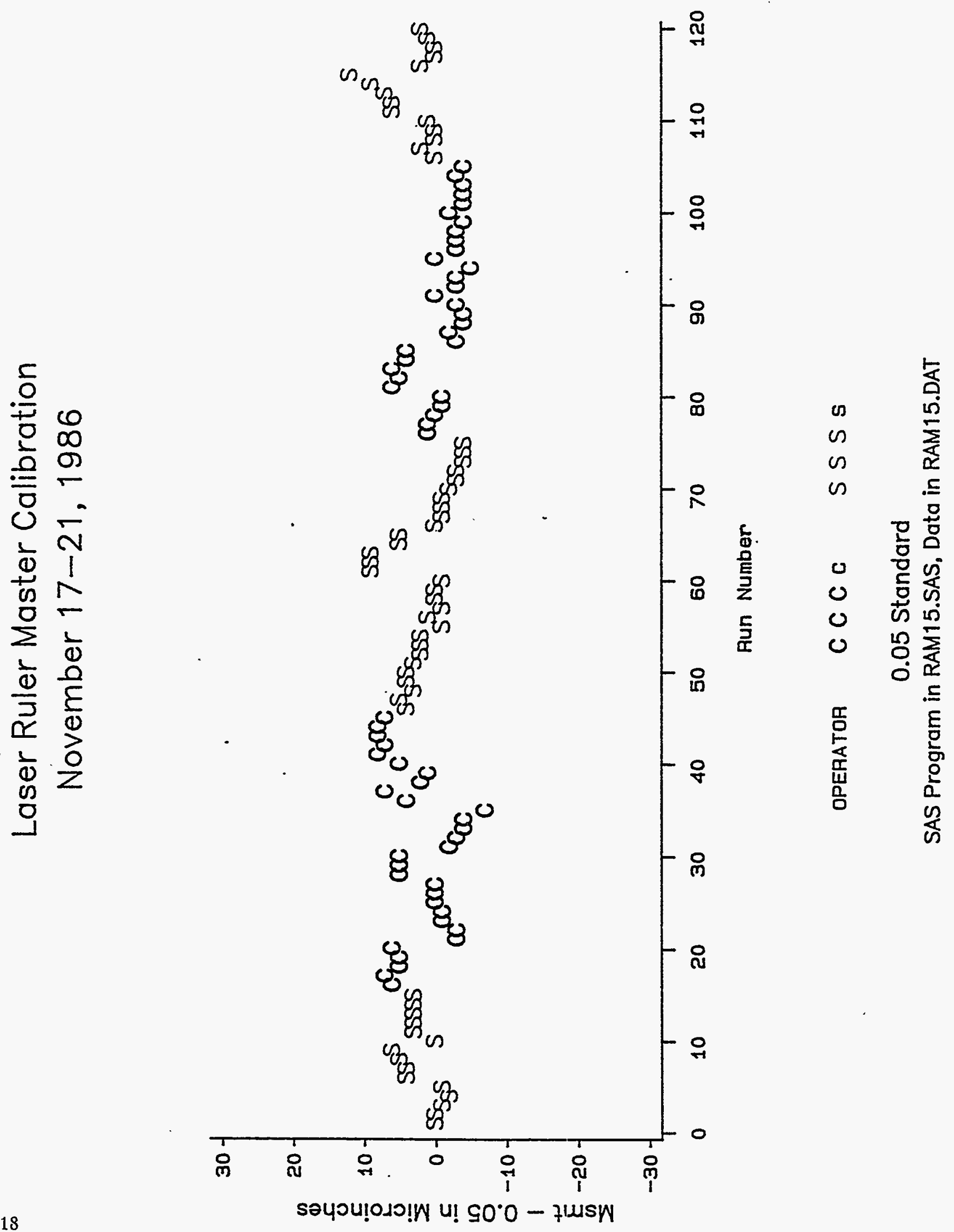


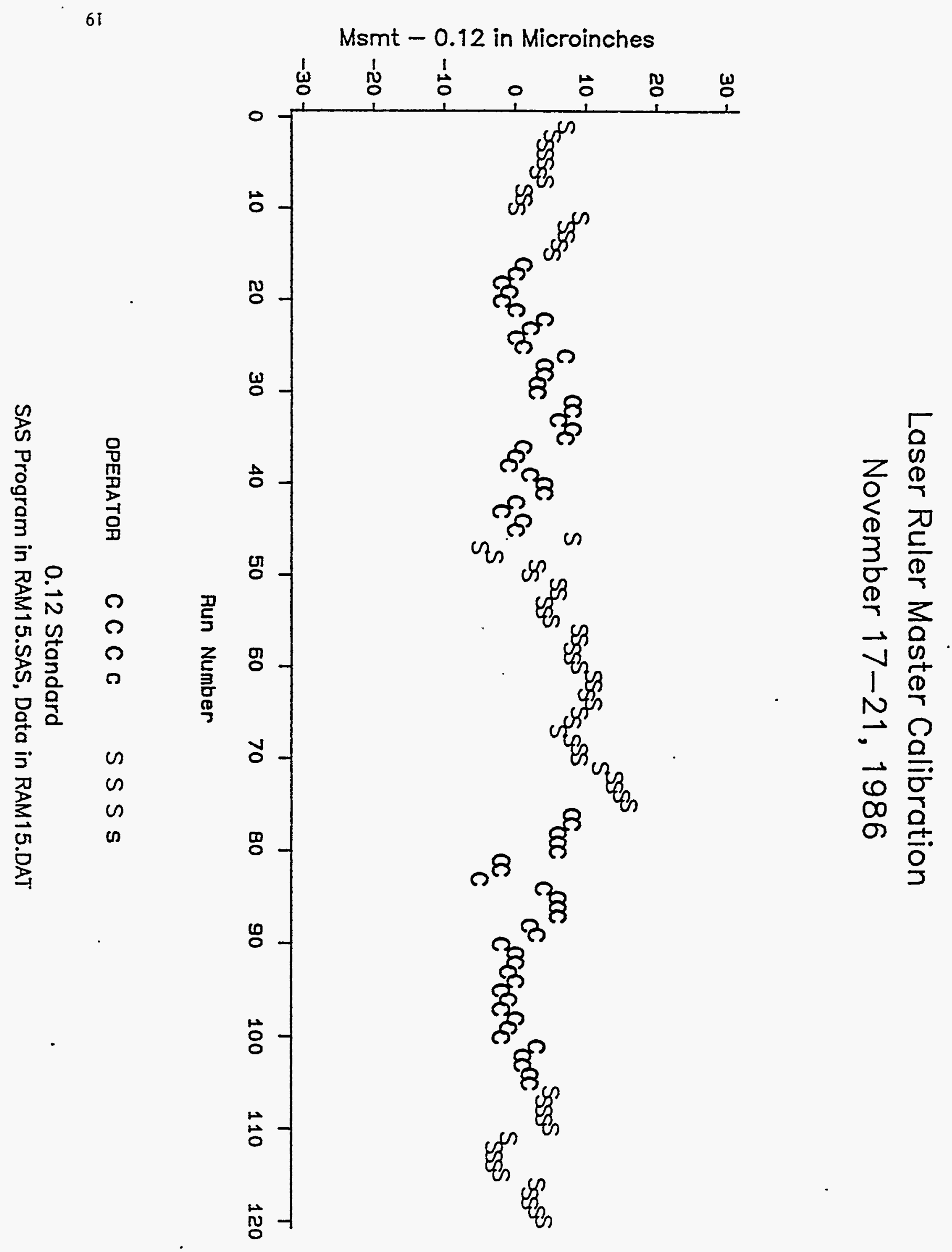


Inter-Office Correspondence

\begin{tabular}{|c|c|}
\hline From & $\begin{array}{l}\text { Administration, Quality Engineering } \\
\text { R. S. Ramachandran }\end{array}$ \\
\hline Date & August 3, 1987 \\
\hline Subject & SPC on Laseruler measurements \\
\hline Reference & $\begin{array}{l}\text { Memo from Warner to Hodapp, dated } 6 / 18 / 87 \\
\text { "Laseruler Control Charts" }\end{array}$ \\
\hline TO & W. J. Stitzel \\
\hline \multicolumn{2}{|r|}{$\begin{array}{l}\text { QE has completed a short term monitoring of Laseruler measurements through SPC } \\
\text { technique ( } X \text { bar and } R \text { charts) and have established the control limits for the } \\
\text { two selected working standards of microclad bridges (WSTD). Attached charts on } \\
\text { standards } 27-027 \text { ( } 200 \text { microinch thickness) and PQ8-800 (168 microinch thickness) } \\
\text { provide the initial control limits for } X \text { bar and } R \text { charts (ignore the sigma } \\
\text { charts). }\end{array}$} \\
\hline \multicolumn{2}{|r|}{$\begin{array}{l}\text { Software modifications for calibration (probe zeroing for four times) and } \\
\text { measurement of the standards (three readings, and calculation of average and } \\
\text { range) are completed by Allen Poe (I \& PA Group). - SPC software implementation } \\
\text { may be added for plotting the control charts after gaining the required hands-on } \\
\text { experience with control charts by Operations. }\end{array}$} \\
\hline
\end{tabular}

The microclad working standards (two WSTD) are being provided to Operations for daily monitoring of Laseruler measurement reliability via SPC technique and to implement the Measurement Assurance Program (MAP) in the future. The third WSTD, steel gage standard, will be provided to you by Process Engineering group (Daryl Greywitt) in three weeks.

Step-by-step instructions for plotting the control charts and identifying an "out-of-control" conditions were explained in the above referenced memo. Technical Manual should be revised for inclusion of an operation sheet for running the Laseruler control charts.

If you need any further assistance please contact me or B.J.Warner.<smiles>[R]NS[R]</smiles> 


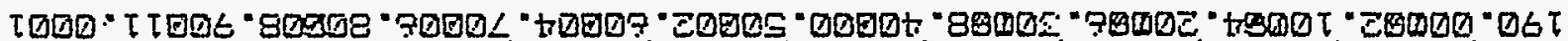
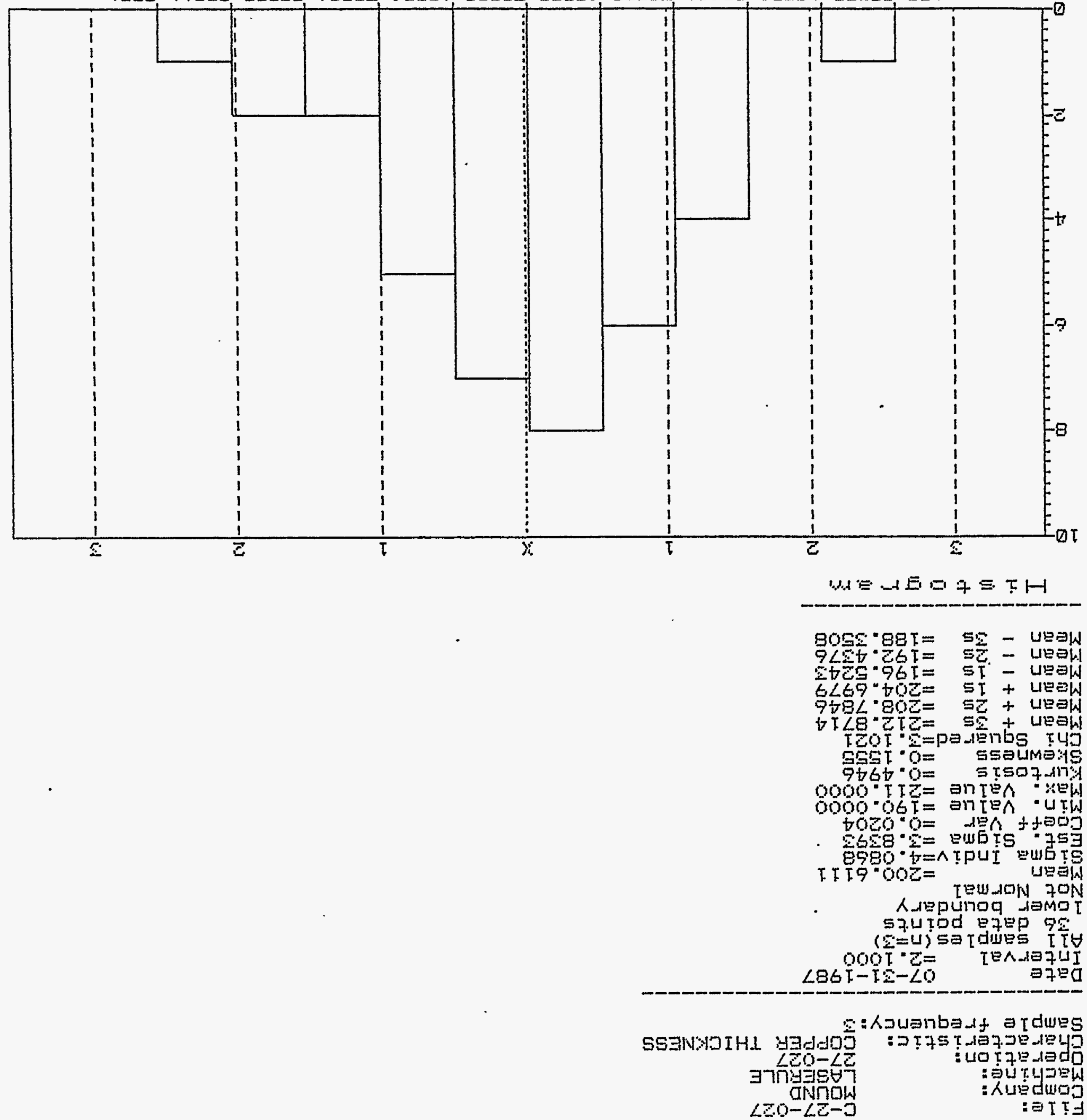

TESET $\angle 86 I-T E-\angle 0$ 
Fi. 1 e:

Company:

Machine:

Fart nlimber : $27-027$.

Characteristic:
Sample frequency:

MIOUND
07-31-1797 15:12

$C-27-027$

LASEFIULE

COFFEF THICKNESS
Siqma Chamt.

$L C L=--\quad H E A H=3.3398 \quad U C L=8.5747$
Fiange Chart.

$\angle C L=-$ HEARE $=6.5$ UCL $=16.731$

USTHG TAEULAF COHSTAHTS, EASEII DH SAMFIES I-12 $x-$ bar Chart.

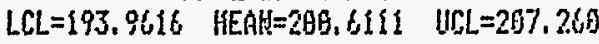

म

10 in

Q

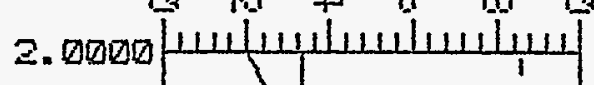
$3.0550 \square \frac{1}{1}$

E. BDE

1.1547

4. 0000

1.5275

F. 00000

3

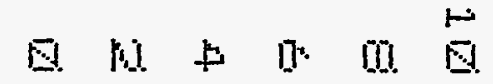

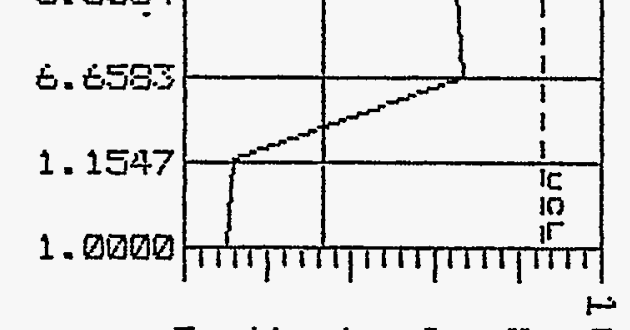

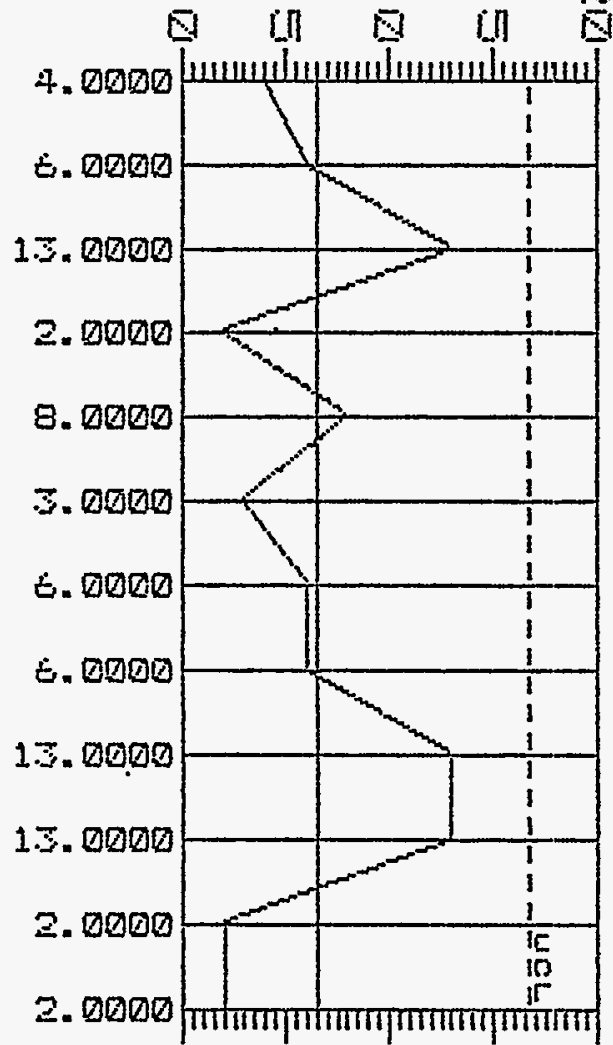

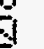

200. 0000 |

205.503

2DE. S.S.

199.0000

205.53

200.0000

$200.3 \%$

$201.6 \pm 67$

197.3 .5

199.

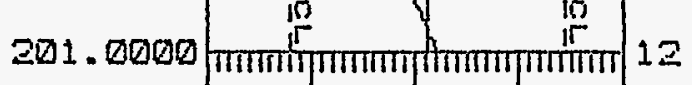

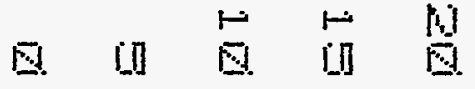

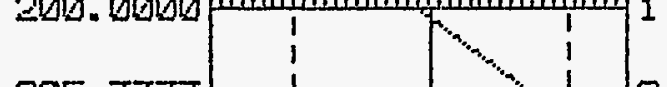

175.6507

\section{Ho samples failed any out-of-contral tests}
\pm 1 Siging $=4.1 .7 \%$
\pm 1 Singhe $=41.7 \%$
\pm 2 sions $=100 \%$
$\pm 2 \operatorname{Sigh}:=100 \%$

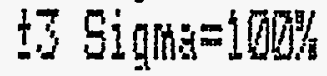

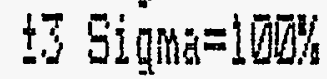
\pm 1 sign: $=58.7 \%$
$\pm 25 \sin i d=91.7 \%$
t5 $\operatorname{sing}:=10 \mathrm{x}$ 


\section{DOFFEF THICHNESS}

File:

Company:

Machine:

operation:

Characteristic:

Sample frequency:

Date

Interval =6.2000

Al I samples ( $n=3$ )

bata points

1 ower boundary

Not Nomal

Mean $=167.6944$

Sigma Indi $v=10.3753$

Est. Sigma $=6.10 .36$

Coeff Var $=0.0619$

Min. VaIlue $=116.0000$

Max. Value $=178.0000$

furtosis $=14.3109$

Sl.EWnesS =-3.4228

Chi Squared $=14,30,39$

Mean $+.5=198.9203$

Mean $+25=188.4450$

Mean + 15 $=178.0697$

Mean $-15=157.3191$

Mean $-25=146 . \overline{7} .58$

Mear - $35=136.5685$

$\mapsto i \equiv ナ \boxminus \boxminus r \equiv m$

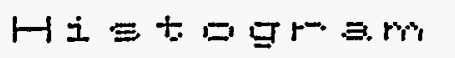

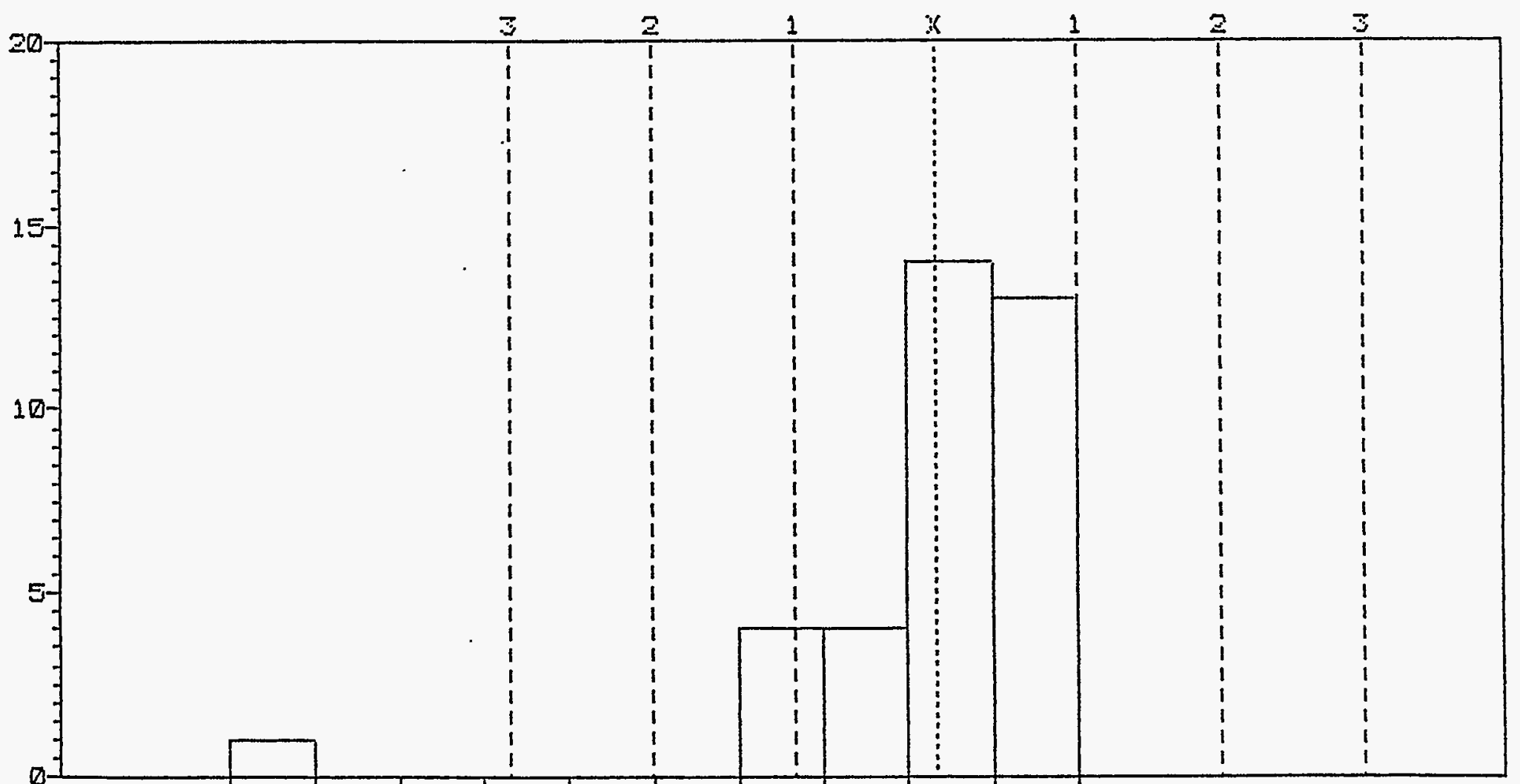

11․0122. 2128. 41.34. ¿140.8147.015..2159.4165.6171.8178.0 


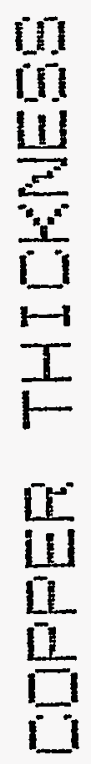
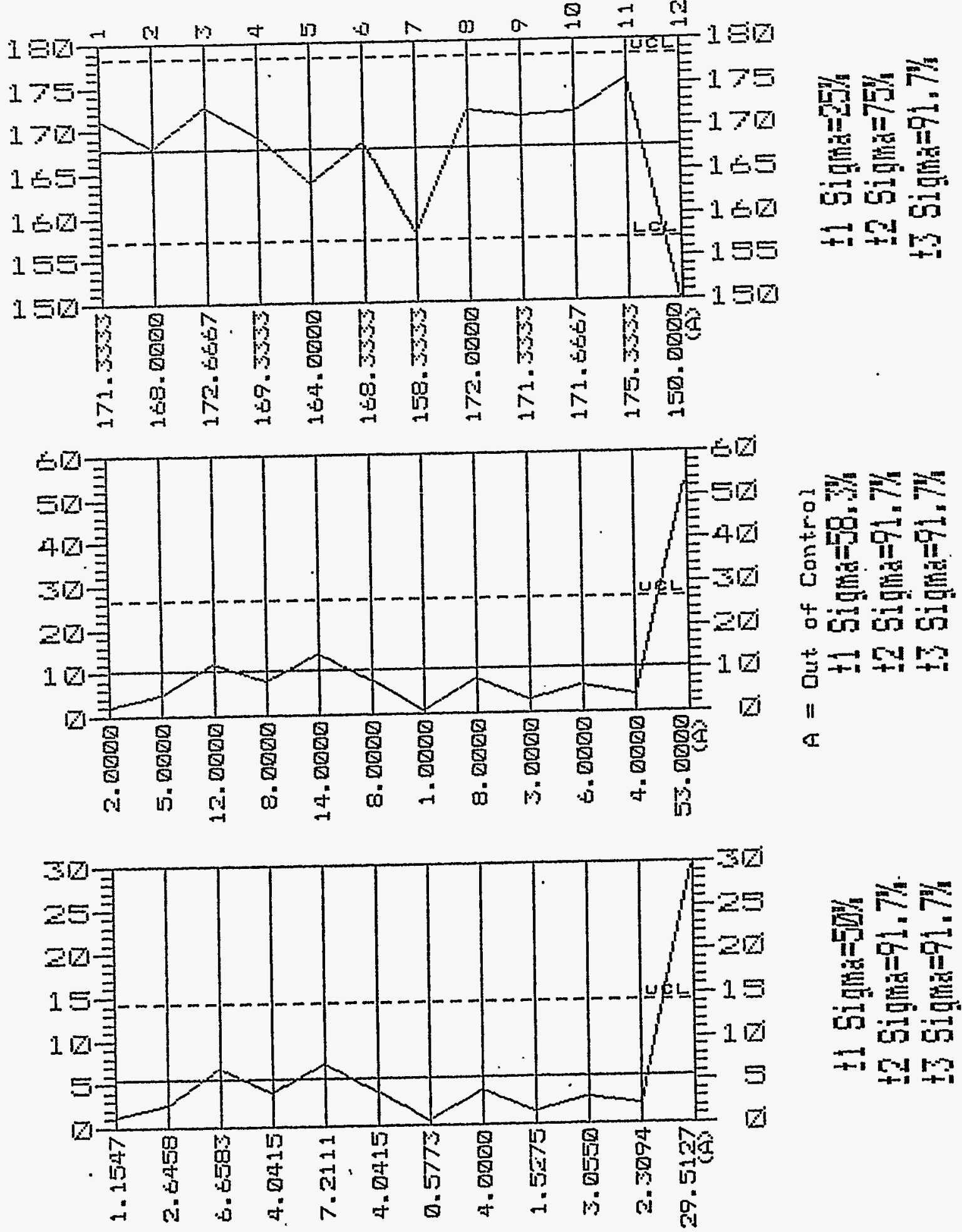

$-\mathrm{F}=$

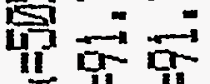

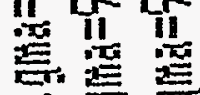
$\underset{. \rightarrow 0}{\ddot{u}}$ in क्य का …足它4

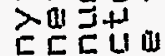
2 西. L

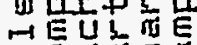

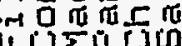




\section{Acknowledgments}

The authors would like to thank S. E. Rigdon and A. L. Poe for their contribution to tape process development. The authors also extend special recognition to those Production, Quality, and Development personnel who contributed to the data collection and reduction. K. P. Armstrong claims no recognition for the research, only for the effort required to document it. 


\section{Glossary}

Artwork

Bridge

Bridge Length

Bridge Width

Eddy Current

Flyer

Kapton

LANL

Laseruler

LLNL

Microclad

Phototool

Radius Bridge

Reel

Receiving Inspection

Roll
See phototool.

Functioning copper foil portion of a slapper that drives the flyer.

Dimension of a bridge parallel to the electric current.

Dimension of a bridge perpendicular to the electric current.

Nondestructive technique for measuring substrate thickness; used to determine copper thickness on bridge (microclad) material.

Portion of a slapper detonator driven by rapid ionization of the bridge element. (usually 0.001 -in. to 0.002 -in. Kapton).

Trade name for a polyimide product produced by duPont.

Los Alamos National Laboratory.

Tool used to nondestructively measure substrate thickness; used to determine copper thickness on finished bridge circuits.

Lawrence Livermore National Laboratory.

Trade name of a copper-coated polyimide produced by Fortin Industries and used in fabricating bridges and flyers.

Tool used to create a circuit image. A phototool contains the image of the desired circuit and exposes the. image onto a chemically conditioned surface.

Bridge for which the length is defined by a radius such that the center of the bridge is in the thinnest region.

Sample of material slit to a width of $35 \mathrm{~mm}$ and wound around a core.

Area at Mound where incoming material is inspected for conformance to specifications.

Sample of material as purchased from a vendor. A roll is the original width, usually 12 in. A roll is later slit to thinner widths to become reels. 
SNLA

Square Bridge

Tape Process

Vidicom

Wet Processing
Sandia National Laboratories, Albuquerque.

Bridge for which the width is uniform from end to end.

Method of producing flexible circuits in a reel-to-reel fashion. This process is unique to Mound.

Vision system produced by Vidicom to inspect bridge length and width.

Process of laminating, exposing, developing, etching, and stripping a flexible circuit image. 


\section{Distribution}

\section{External}

S. G. Barnhart, Sandia National Laboratories, Albuquerque

G. E. Dahms, Sandia National Laboratories, Albuquerque

R. McCormick, Los Alamos National Laboratory

J. A. Morley, DOE/DAO

\section{Internal}

K. P. Armstrong

J. R. Brinkman

T. M. Bruggeman

T. A. Demana

R. A. Fischbein

M. P. Fisher

E. D. Freese

E. D. Hill

G. L. Houston

M. A. Huelskamp

C. W. Huntington

D. P. Kelly

D. E. Michel

G. L. Morris

R. S. Ramachandran

M. D. Stoltz

J. A. Thomes

R. E. Vallee

S. I. Waskey

W. Yurkowsky, Jr.

Library (10)

Publications 